\title{
A search for RNA insertions and NS3 gene duplication in the genome of cytopathic isolates of bovine viral diarrhea virus
}

V.L. Q uadros, S.V. Mayer, F.S.F. Vogel, R. W eiblen, M.C.S. Brum, S. Arenhart and E.F. Flores
Setor de Virologia, Departamentos de Medicina Veterinária Preventiva, M icrobiologia e Parasitologia, Universidade Federal de Santa M aria, Santa Maria, RS, Brasil

\section{Correspondence \\ E.F. Flores \\ Departamento de Medicina \\ Veterinária Preventiva, UFSM \\ 97105-900 Santa Maria, RS \\ Brasil \\ Fax: + 55-55-3220-8034 \\ E-mail: flores@ ccr.ufsm.br}

Research supported by MCT, CN Pq, CAPES, and a FINEP grant (PRONEX

em Virologia Veterinária, No. 215/96).

E.F. Flores and R. Weiblen are recipients of CN Pq fellowships (Nos. 101666/2004-0 and 301339/2004-0, respectively). V.L. Q uadros and S.V.

Mayer are $\mathrm{MS}$ students with $\mathrm{CNPq}$ fellowships.

Received September 12, 2005 Accepted March 29, 2006

\section{Abstract}

Calves born persistently infected with non-cytopathic bovine viral diarrhea virus (ncpBVDV) frequently develop a fatal gastroenteric illness called mucosal disease. Both the original virus (ncpBVDV) and an antigenically identical but cytopathic virus (cpBVDV) can be isolated from animals affected by mucosal disease. Cytopathic BVDVs originate from their $n c p$ counterparts by diverse genetic mechanisms, all leading to the expression of the non-structural polypeptide NS3 as a discrete protein. In contrast, ncpBVDVs express only the large precursor polypeptide, NS2-3, which contains the NS3 sequence within its carboxy-terminal half. We report here the investigation of the mechanism leading to NS3 expression in $41 \mathrm{cpBVDV}$ isolates. An RT-PCR strategy was employed to detect RNA insertions within the NS2-3 gene and/or duplication of the NS3 gene, two common mechanisms of NS3 expression. RT-PCR amplification revealed insertions in the NS2-3 gene of three $c p$ isolates, with the inserts being similar in size to that present in the cpBVDV NADL strain. Sequencing of one such insert revealed a 296-nucleotide sequence with a central core of 270 nucleotides coding for an amino acid sequence highly homologous $(98 \%)$ to the NADL insert, a sequence corresponding to part of the cellular J-Domain gene. One cpBVDV isolate contained a duplication of the NS3 gene downstream from the original locus. In contrast, no detectable NS2-3 insertions or NS3 gene duplications were observed in the genome of $37 \mathrm{cp}$ isolates. These results demonstrate that processing of NS2-3 without bulk mRNA insertions or NS3 gene duplications seems to be a frequent mechanism leading to NS3 expression and BVDV cytopathology.

\section{Introduction}

Bovine viral diarrhea virus (BVDV) is an important pathogen of cattle which causes significant economic losses to the livestock

\section{Key words}

- Bovine viral diarrhea virus

- cpBVDV

- NS3 gene

- Cytopathology

- RNA processing industry around the world (1). BVDV is a small enveloped RNA virus belonging to the Flaviviridae family, genus Pestivirus, along with classical swine fever virus and border disease virus of sheep $(1,2)$. The BVDV 
genome is a linear, single-stranded, positive sense RNA molecule of approximately 12.5 $\mathrm{kb}$ in length (3). The genome contains a single large open reading frame (ORF) encoding a polyprotein of about 3900 amino acids. The ORF is flanked by a 5' 381-386nucleotide long untranslated region (5'UTR) and by a 3' 229-nucleotide long UTR (3). The 5'UTR contains a secondary structure believed to act as an internal ribosomal entry site to direct the translation of the ORF upon internalization of the viral genome into the host cell (4). Translation of the ORF produces a long polyprotein, which is co- and post-translationally processed by viral and cellular proteases giving rise to 11 to 12 mature viral proteins $(3,5)$. The structural proteins (the exception is $\mathrm{N}^{\text {pro }}$, a non-structural protein) are encoded by the 5 ' third of the genome as follows: N ${ }^{\text {pro }}, \mathrm{C}, \mathrm{E}^{\mathrm{rns}}, \mathrm{E} 1, \mathrm{E} 2$, and p7. Non-structural proteins are encoded downstream: NS2-3, NS4A, NS4B, NS5A, and NS5B (Figure 1) $(3,5,6)$. The vast majority of BVDV field isolates do not induce cytopathology in cell culture and are called non-cytopathic ( $n c p)$; cytopathic ( $c p)$ isolates are found almost exclusively in cattle suffering from mucosal disease $(6,7)$.

Infection of seronegative cattle with BVDV may result in a variety of clinical manifestations ranging from inapparent infections to gastroenteric, respiratory, hemorrhagic syndrome, severe acute BVDV, and the fatal mucosal disease (7-9). Infection of pregnant cows is often associated with reproductive losses, including early or late embryonic or fetal deaths, abortion or mummification, congenital malformations, stillbirths and the birth of weak, non-thriving calves $(8,10)$. Fetuses infected between 40 and 120 days of gestation with $n c p$ isolates may survive the infection and be born as immunotolerant, persistently infected calves $(8,10)$. Most persistently infected animals develop and die of mucosal disease within the first 6 to 24 months of life; $c p$ and $n c p$ BVDV biotypes can usually be isolated from sick animals $(7,8,10)$. Cytopathic and noncytopathic viruses isolated from cases of mucosal diseases are antigenically identical to each other and constitute what has been called a virus pair $(7,11)$. Molecular analyses of $c p-n c p$ pairs have indicated that the $c p$ virus originates from the original $n c p$ counterpart by diverse genetic mechanisms (12-17).

The most important molecular difference between the $c p$ and $n c p$ biotypes of BVDV is the expression of the non-structural polypeptide NS3 (formerly known as p80). Whereas ncpBVDVs express a single polypeptide of approximately $125 \mathrm{kDa}$ called NS2-3 (or p125), cpBVDVs express both the entire NS2-3 and NS3, a separate protein which corresponds to the carboxy-terminal two thirds of NS2-3 (Figure 1) $(5,11)$. NS23 is a multifunctional protein believed to be involved in several steps of viral replication. It contains a zinc finger motif and a hydrophobic domain in its amino-terminal third (NS2), and helicase, NTPase and protease
Figure 1. Organization of the bovine viral diarrhea virus genome and processing of the NS2-3 polypeptide in cytopathic (cp) and non-cytopathic (ncp) isolates. In ncp isolates, NS2-3 is expressed as a single-long polypeptide; in $\mathrm{cp}$ isolates both the entire NS2-3 and NS3 polypeptides are found. In cp viruses, NS3 expression may result from NS2-3 cleavage or translation of a duplicated gene. UTR = untranslated region.

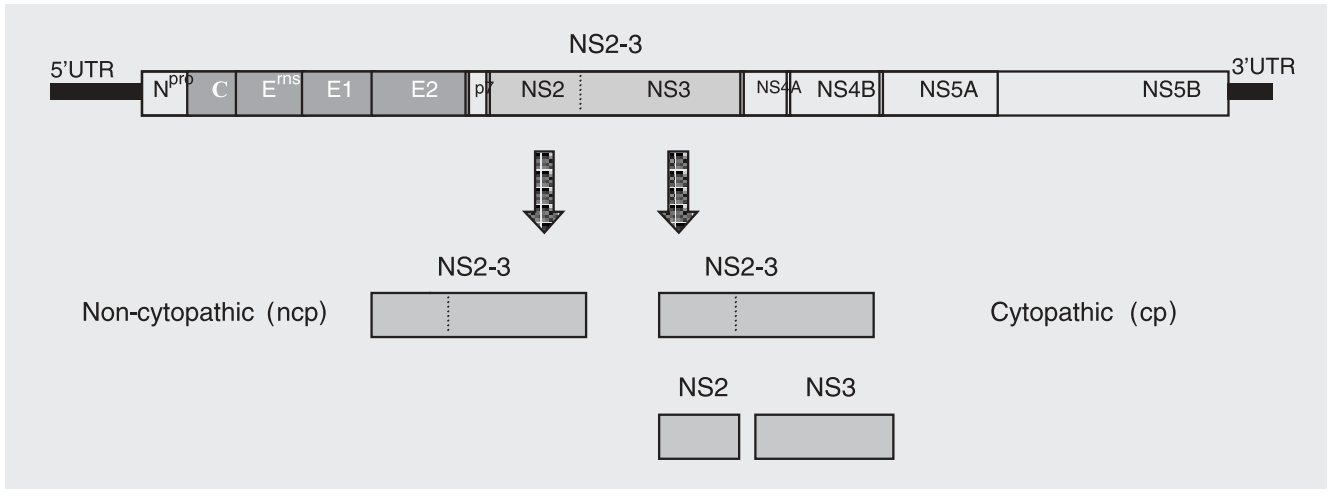


motifs in its carboxy-terminal half (NS3) $(5,6)$. Although the expression of NS3 as a single polypeptide is the molecular marker of cpBVDV isolates, its exact role in the production of cytopathology is still unclear.

Several mechanisms of expression of NS3 by $c p$ viruses have been described, including insertions of cellular RNA sequences in NS23 near the boundary between NS2 and NS3 $(12,13)$, downstream duplication of the NS3 gene (16); expression of NS3 from a defective RNA genome (15), point mutations in the NS2-3 gene (14), and insertions of cellular sequences plus viral gene duplications in the N-terminus of the polyprotein (17).

The differential expression of NS3 and its contribution to BVDV cytopathology in vitro and the pathogenesis of mucosal disease in vivo constitute a major issue in pestivirus biology and pathogenesis and have been a matter of intensive investigation in the last two decades. The number of possible mechanisms of NS3 expression - and therefore, the generation of $c p$ viruses - increases as more $\mathrm{cpBVDV}$ isolates are characterized.

The molecular mechanism of NS3 expression was investigated here by searching for insertions and/or gene duplications in the genome of $41 \mathrm{cpBVDV}$ isolates. RNA insertions were detected in three isolates, NS3 duplication in one, and 37 isolates showed no detectable genomic alterations.

\section{Material and Methods}

Forty-one cytopathic isolates of BVDV were biologically cloned to obtain pure cpBVDV. Individual $c p$ clones were then propagated and their genomic RNA was extracted and submitted to RT-PCR analysis for the presence of insertions in NS2-3, close to the boundary between the NS2 and NS3 genes, and for duplications of the NS3 gene. The viral genomes containing insertions and/ or duplications were partially sequenced to determine the nature of the genomic rearrangements.

\section{Cells and viruses}

All procedures of virus multiplication, quantitation and plaque assays for biological cloning were performed in pestivirusfree Madin-Darby bovine kidney cells (MDBK, American Type Culture Collection, Rockville, MD, USA). Cells were maintained in minimal essential medium containing $1.6 \mathrm{mg} / \mathrm{L}$ penicillin, $0.4 \mathrm{mg} / \mathrm{L}$ streptomycin, and $0.0025 \mathrm{mg} / \mathrm{L}$ fungizone, supplemented with $5 \%$ horse serum. Sixty cytopathic BVDV isolates obtained from cases of mucosal disease were kindly provided by Dr. Fernando A. Osorio (Department of Veterinary and Biomedical Sciences, University of Nebraska at Lincoln, UNL, Lincoln, NE, USA). After isolation in primary bovine lung cells and identification by fluorescent antibody assay, the viruses were further propagated in MDBK cells. The standard BVDV strains cpSinger, cpNADL, cpOregon, and cpTGAC were provided by Dr. Ruben O. Donis (Department of Veterinary and Biomedical Sciences, UNL, Lincoln, NE, USA).

\section{Biological cloning of cytopathic viruses}

After propagation in MDBK cells, the isolates were biologically cloned in order to obtain pure $c p$ virus clones and further propagated. Biological cloning for $c p$ viruses was performed by standard plaque assays and the purified $c p$ viruses were propagated and submitted to RT-PCR analysis.

\section{RNA preparation}

MDBK cells grown in $\mathrm{T}-25-\mathrm{cm}^{2}$ flasks were infected with each clone of $c p$ virus at a multiplicity of infection of 0.1 to 1 . When the cytopathic effect reached approximately $70 \%$ of the monolayer (typically 36 to $48 \mathrm{~h}$ post-inoculation), cells were harvested by trypsinization followed by resuspension in culture medium and centrifugation at 3,000 
$g$ for $10 \mathrm{~min}$. The cell pellet was submitted to total RNA extraction using Trizol reagent, according to the manufacturer's protocol (Gibco-BRL, Carlsbad, CA, USA). The RNA pellet was rinsed with $70 \%$ ethanol and resuspended in $50 \mu \mathrm{L}$ diethylpyrocarbamate (DEPC)-treated water. All procedures of RNA manipulation were performed using disposable pipettes and tubes and DEPCtreated water.

\section{Primers}

Oligonucleotide primers corresponding to conserved sequences of the published cpNADL and cpOsloss genomes were used (17). The sequences of the primers are listed below: primer 11 (cDNA primer) 5'-CTGTT GTTGCTTTGGCAA-3' (position 57035686); primer 10 (PCR primer) 5'-GGACTTT ATGTACTAC-3' (4546-4564); primer 14 (PCR primer) 5'-TCCCAATGATAACAG ACATA-3' (7545-7564). The strategy used for detection of insertions or gene duplication was based on previous reports on the location of insertions of cellular mRNA in the viral genome $(17,18)$. Primers 10 and 11 were used for detection of insertions in the

Figure 2. RT-PCR strategy used for the detection of rearrangements in the bovine viral diarrhea virus (BVDV) genome. A, Detection of possible RNA insertions at the junction between NS2 and NS3. Primer 11 (56865703 ) is $286 \mathrm{bp}$ downstream of the ubiquitin insertion site in Osloss and is complementary to the viral genome. Primer 10 (4546-4564) is $450 \mathrm{bp}$ upstream of the cellular insertion site in NADL. B, Detection of possible duplications of the NS3 gene. Primer 14 (7545-7564) is $450 \mathrm{bp}$ upstream of the proposed $3^{\prime}$ and of NS3. PCR using the firststrand BVDV CDNA as template and primers 11 and 14 should not generate any product since the two primers go in opposite directions. A product would be obtained only when the NS3 gene is duplicated $(17,18)$.
A

With insertion

B

With duplication
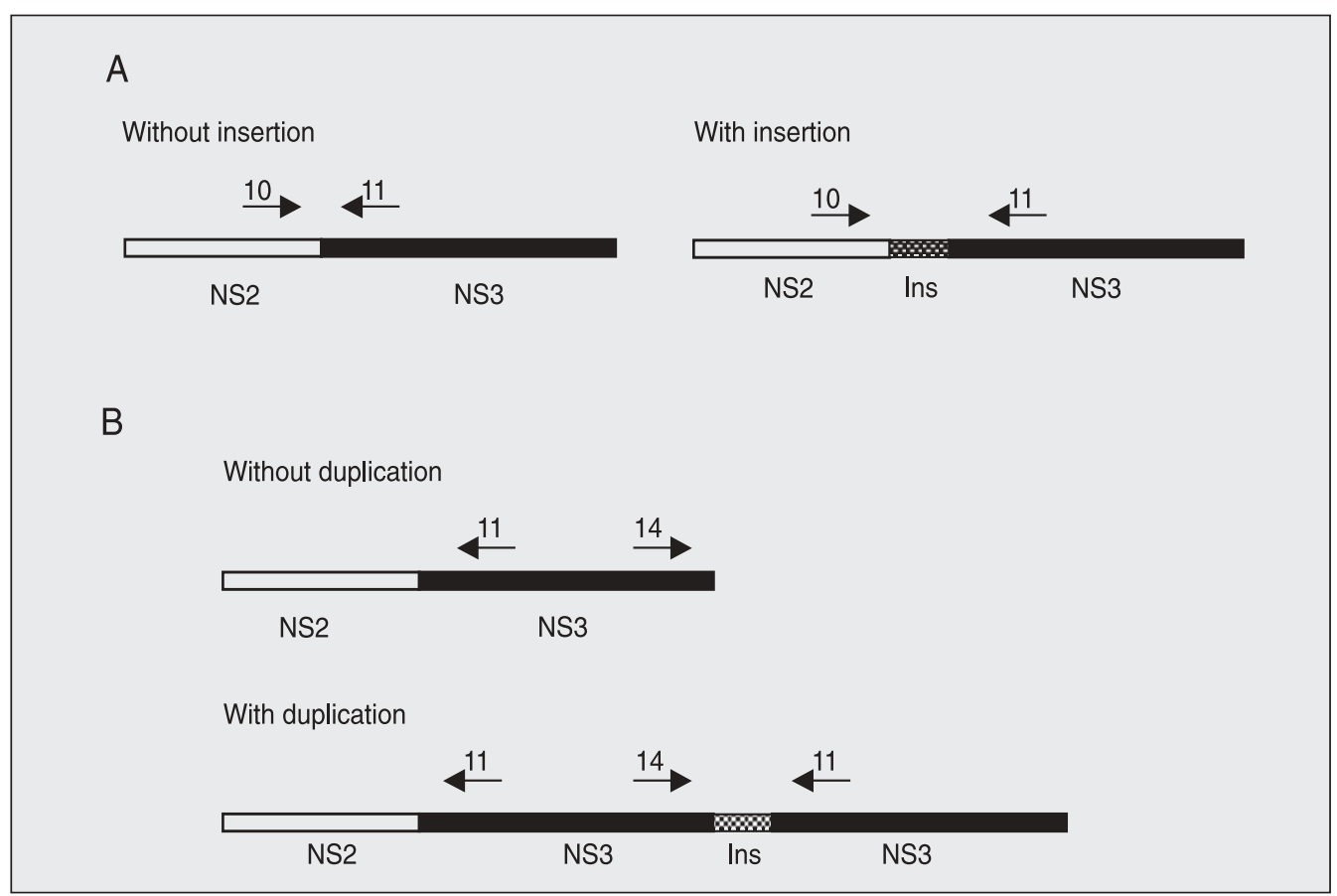

NS2-NS3 gene boundary and primers 11 and 14 were used to detect downstream duplication of the NS3 gene (Figure 2) (17).

\section{RT-PCR amplification}

RNAs from all $c p$ clones were initially submitted to RT-PCR using primers 10 and 11 (for insertions). RNAs of the standard cpBVDVs Singer and NADL were used as positive controls. Total RNA extracted from mock-infected MDBK cells was used as negative control and subsequently, submitted to RT-PCR using primers 11 and 14 (for NS3 gene duplication). RNAs from TGAC, a virus containing an NS3 gene duplication downstream from the original gene (17), were used as control. RT-PCR was performed in a $50-\mu \mathrm{L}$ reaction using the Ready-to-Go RT-PCR Beads kit (Amersham Biosciences, Piscataway, NJ, USA), according to manufacturer recommendations. Briefly, $44 \mu \mathrm{L}$ DEPC-treated water was added to $2 \mu \mathrm{L}$ of the RNA suspension (approximately $1 \mu \mathrm{g}$ of total RNA) and $2 \mu \mathrm{L}$ of each primer (100 ng each) and mixed with the RT-PCR beads preparation. Each $50-\mu \mathrm{L}$ reaction contained 2 units of Taq DNA polymerase, $10 \mathrm{mM}$

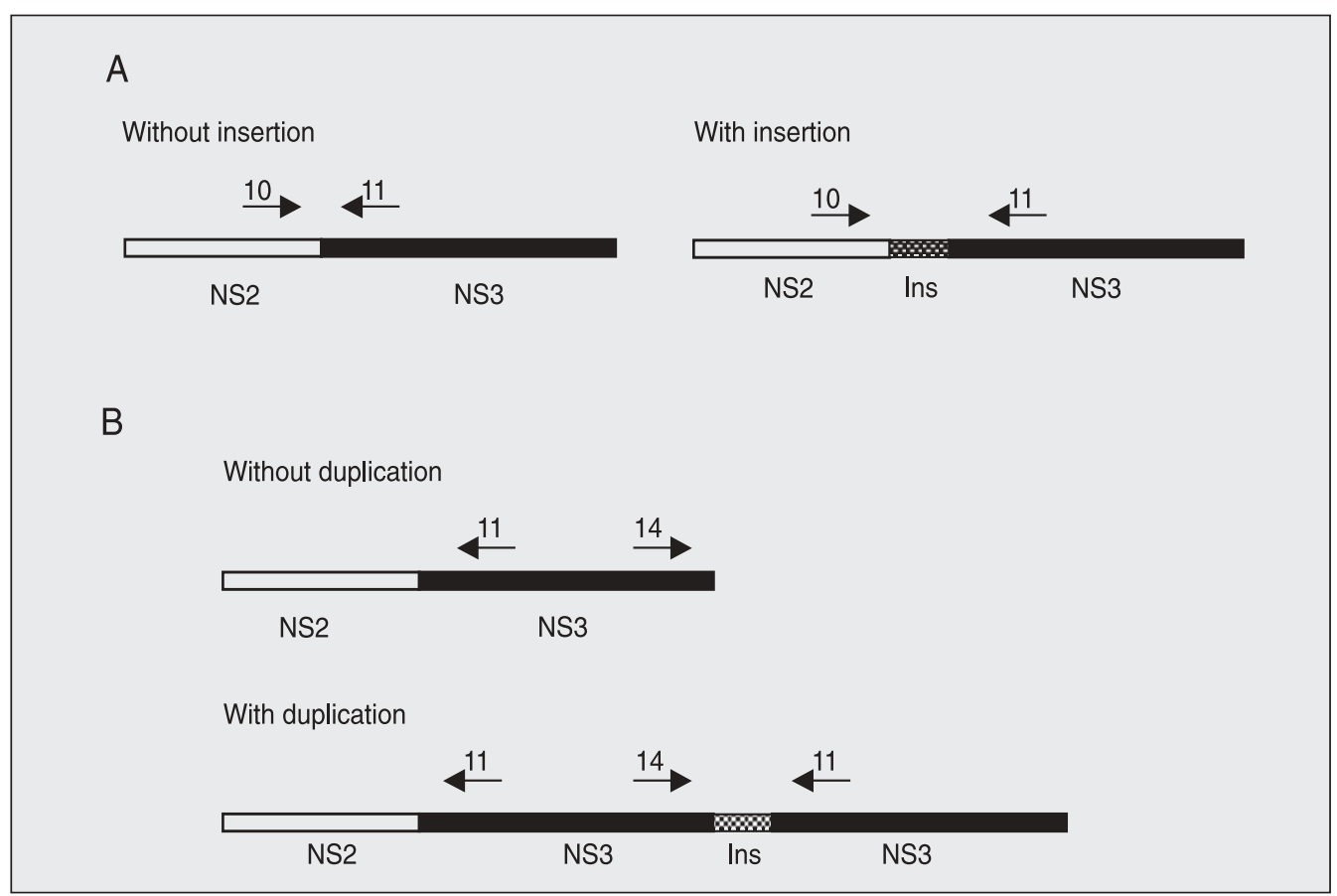


Tris- $\mathrm{HCl}, \mathrm{pH} 9.0,60 \mathrm{mM} \mathrm{KCl}, 1.5 \mathrm{mM}$ $\mathrm{MgCl}_{2}, 200 \mu \mathrm{M}$ of each dNTP, MuLV reverse transcriptase, RNAse inhibitor and stabilizers. The tubes were incubated for 20 min at $42^{\circ} \mathrm{C}$ for $\mathrm{RT}$ and $5 \mathrm{~min}$ at $95^{\circ} \mathrm{C}$ and then submitted to 35 cycles of $95^{\circ} \mathrm{C}$ for 1 min, $50^{\circ} \mathrm{C}$ for $1 \mathrm{~min}$ and $72^{\circ} \mathrm{C}$ for $1 \mathrm{~min}$, followed by an extension of $5 \mathrm{~min}$ at $72^{\circ} \mathrm{C}$. RT-PCR products were visualized under UV light on ethidium bromide-stained $1 \%$ agarose gel after electrophoresis.

\section{Nucleotide sequencing and analysis}

The 4 amplicons were directly purified by polyethyleneglycol precipitation (19). DNA sequencing was then performed directly from the purified amplicons using a MegaBACE 500 (Amersham Biosciences Corp., Piscataway, NJ, USA) automatic sequencer. The dideoxi chain-termination reaction was implemented with the use of the DYEnamic $\mathrm{ET}^{\circledR}$ kit (Amersham) and the primers 10 and 11. Sequence analysis and sequence alignments were performed with the Clone Manager Professional Suite, Align plus 5, version 5.10, software (Sci Ed. Central, Cary, NC, USA).

\section{Results}

Sixty BVDV isolates which produced cytopathology upon virus isolation in bovine lung cells were initially propagated in MDBK cells. Since field cpBVDV isolates usually contain a mixture of related $c p$ and $n c p$ viruses - called a virus pair (11), the isolates were biologically cloned by plaque assay to yield pure populations of each $c p$ counterpart. For some isolates, plaque purification was performed twice or even three times to ascertain the purity of the cloned $c p$ viruses. The identification of each isolate was confirmed on the basis of the characteristic cytopathology and by fluorescent antibody assay (data not shown). After plaque purification, cloned $c p$ viruses were propa- gated in MDBK cells to produce viral stocks and subsequently used to infect cells for RNA extraction. For some isolates, biological cloning of the $n c p$ counterparts was performed by limiting dilution. Forty-one pure clones of cpBVDV were further used in the study. In the remaining $19 \mathrm{cp}$ isolates, biological cloning of pure $c p$ viruses could not be achieved.

Total RNA extracted from cells infected with each of the 41 cloned cpBVDV was initially submitted to RT-PCR amplification using primers 10 and 11 . In viral genomes lacking insertions within the NS2-3 gene, the PCR product obtained by using these primers should be a 900-bp fragment (Figures 2 and 3) (17). RNA extracted from cells infected with the cpBVDV Singer strain, a virus known to lack cellular insertions in the NS2-3 gene (14), and the RNA from the cpBVDV NADL strain, whose genome contains a 270-nucleotide insert (12), were used as controls. RT-PCR amplification of the RNA of $38 \mathrm{cpBVDV}$ with primers 10 and 11 produced amplicons indistinguishable in size from that of the Singer strain (Table 1, Figure 3). Further separation of DNA fragments by extending the time of electrophoresis did not permit detection of size differences among these amplicons (data not shown).

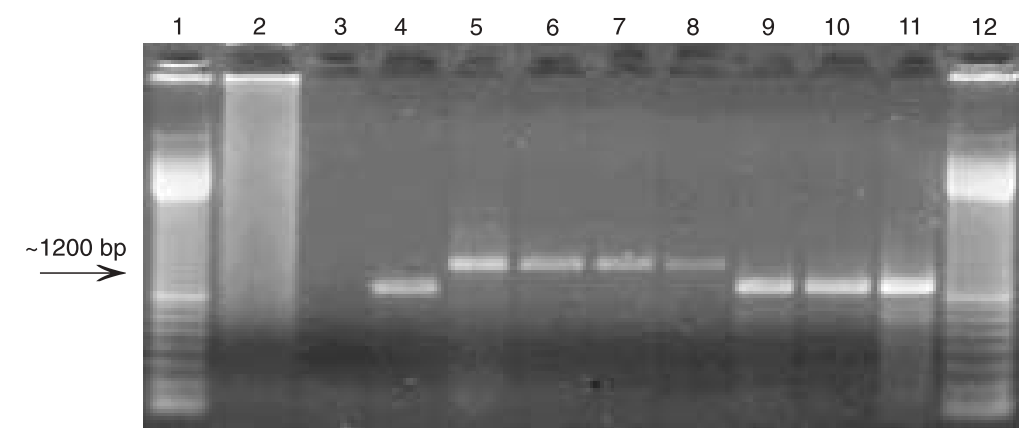

Figure 3. RT-PCR analysis for the detection of insertions in the NS2-3 gene in the cytopathic bovine viral diarrhea virus isolates. Lane 1, Molecular weight marker (100-bp ladder); lane 2, negative control; lane 3, no template; lane 4, Singer strain; lane 5, NADL strain; lane 6, isolate 26 ; lane 7, isolate 44 ; lane 8 , isolate 63 ; lane 9 , isolate 13 ; lane 10 , isolate 33 ; lane 11 , isolate 73 ; lane 12 , molecular weight marker. RT-PCR products were submitted to $1 \%$ agarose gel electrophoresis, stained with ethidium bromide and visualized under UV light. The size of the amplified products from isolates containing inserts is indicated by the arrow. 
A

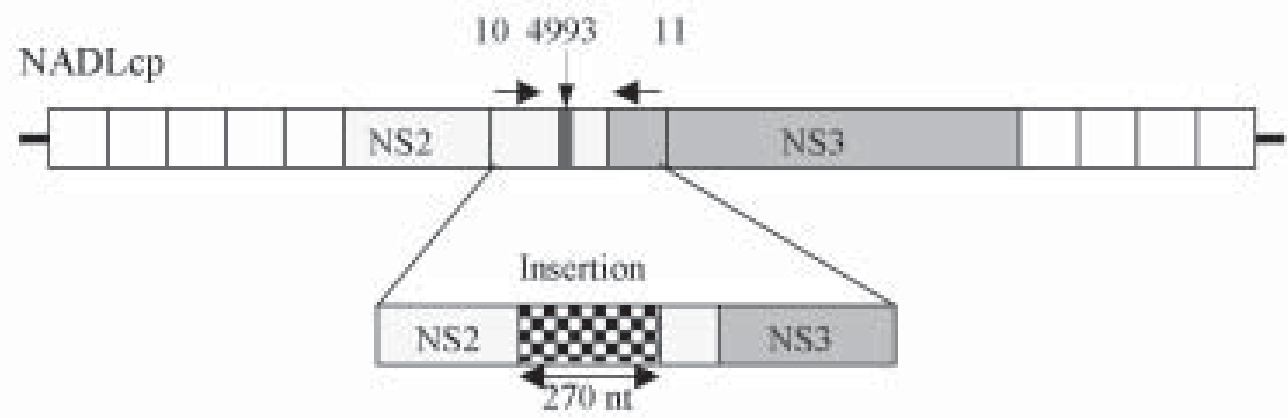

B

NS2

4993

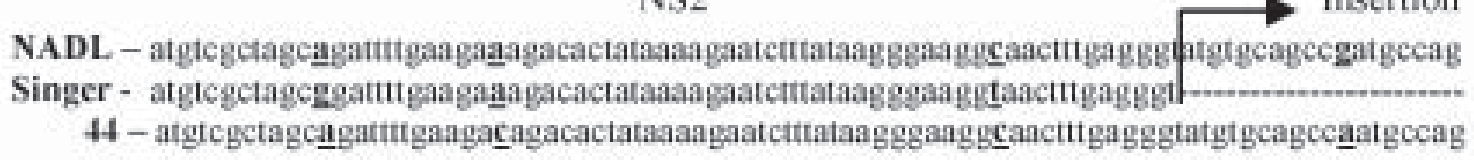
ggaangcataggaggttgnaatggaocgggaacctaagagtgccagatactgtgctgagtgtaataggctgcatectgctgaggaggtgact ggaaagcataggaggttgaagt ggaccgggaacctaagattgccagatactgtgetgagtgtaataggctgeattetgctgaggaaggtgact ttgggcagagtcgagcatgtgggectcaaaatcacctacttgcgetgatggatggaaaggtatatgatatcacagagtgggctggatgccagc ttgggcagagtcgagcatgttgggectcaaaatcacctactttgegctgatggatggaaacgtecatgatatcacagagtgggetggatgecage gtgtgggaatctccccagatacccacagagtccettgtcacatctcattggttcacggatgcctttcaggcaggaggaatacaatggctttgtacaa gtgtgggatctcccagatacccacagagtcccttgtcacatctcattggttcacggat fotttcaggcaggaggaatacaatggctttgtacaa tataccgctageggecaectattictg $4994 \quad \mathrm{NS} 2$ tataccgetaggggecaattacitgtg tataccgctagggggcaactattictg

C

J-Domain - atgtgcagccgatgccagggaangcataggaggttgaantggaccgggaacctaagagtgccagatactgtgctgagtg Insertion 44. 스. g. 1.

taataggctgcatectgctgaggaaggtgactttgggcagagtcaagcatgttgggcctcaaaatcacctacttgcgctgatggatggaanggtgt _. I atgatatcacagagtgggctggatgecagcgtgtgggatcteccagataccacagagtcecttatcacatctcattggtcacggatg

Figure 4. Sequence alignment of the amplicons obtained with primers 10 and 11 of bovine viral diarrhea virus (BVDV) isolates NADL, Singer, and 44 in the NS2-3 region. The number identifies the published NADL sequence. A, Diagram of the genome of BVDV NADL strain showing the location of the insert within the NS2-3 gene. B, Alignment of sequences of NADL, Singer and isolate 44 in the region corresponding to the insert. C. Alignment of sequences of insertion of isolate 44 and the cellular J Domain protein. The difference in sequences is given in bold and underlined. $\mathrm{cp}=$ cytopathic; $\mathrm{nt}=$ nucleotide . 
Therefore, the genome of the $38 \mathrm{cpBVDV}$ isolates examined does not contain insertions within the NS2-3 in the region comprised between primers 10 and 11 , as ascertained by agar gel electrophoresis of PCR products. The possible mechanisms of NS3 expression by these viruses will be discussed later.

The genome of cpBVDVs 26, 44, and 63 harbors insertions in the NS2-3 gene which are indistinguishable in size from the insertion present in the NADL strain, as ascertained by agar gel electrophoresis. The amplicons obtained by PCR amplification of genomes of cpBVDVs 26, 44, and 63 were then submitted to nucleotide sequencing to determine the nature of the insertion present in these genomes. After several sequencing attempts, only the PCR product of isolate 44 yielded a reliable sequence that could be edited and analyzed. The insert is 296 nucleotides long and contains a core sequence (270 nucleotides) which is $98 \%$ identical and whose predicted amino acid sequence is $100 \%$ identical to the cIns insert present in the genome of the NADL strain. (Figure 4). This insert is highly homologous to a sequence within the bovine gene coding for the J-Domain and is likely to result from recombination between the viral and cellular RNAs during genome replication (20). In the sequences of the other amplicons (cpBVDVs 26 and 63) stretches of mixed nucleotides were frequently observed, probably reflecting co-amplification of different products.

After the first round of RT-PCR with primers 10 and 11, the RNAs of all 41 cpBVDV clones were submitted to another amplification reaction using primers 11 and 14. These primers were designed to detect possible duplications of the NS3 gene (Figure 2). RNA from the TGAC strain, whose genome contains a downstream insertion of ubiquitin RNA plus a duplication of the NS3 gene (17), was used as positive control. The RNA of the Singer strain, which contains no genome rearrangement, was used as negative control. The amplicon produced by primers 11 and 14 in TGAC genome is about 900 bp (17). The use of primers 11 and 14 resulted in RT-PCR amplification in only one cpBVDV isolate (Table 1, Figure 5). The amplicon generated for cpBVDV 14 was smaller than the TGAC amplicon, with an estimated size of about 800-850 bp (Figure 5). No other cpBVDV isolate originated amplicons in the reactions using primers 11

Table 1. Summary of RT-PCR analysis of the genome of cytopathic bovine viral diarrhea virus isolates for insertions in the NS2-3 gene and duplications of the NS3 gene.

\begin{tabular}{|c|c|c|c|c|c|}
\hline Genetic mechanism & Primers & $\begin{array}{l}\text { Isolates } \\
\text { (N) }\end{array}$ & $\begin{array}{l}\text { Amplicon } \\
\text { size (bp) }\end{array}$ & $\begin{array}{l}\text { Negative } \\
\text { isolates ( } \mathrm{N} \text { ) }\end{array}$ & $\begin{array}{l}\text { Amplicon } \\
\text { size (bp) }\end{array}$ \\
\hline $\begin{array}{l}\text { Insertion in the } \\
\text { NS2-3 gene }\end{array}$ & 10 and 11 & 3 & $\sim 1200$ & 38 & $\sim 900$ \\
\hline $\begin{array}{l}\text { Duplication of the } \\
\text { NS3 gene }\end{array}$ & 11 and 14 & 1 & $\sim 850$ & 40 & None \\
\hline Undetermined & $\begin{array}{l}10 \text { and } 11 \\
11 \text { and } 14\end{array}$ & $\begin{array}{l}37 \\
40\end{array}$ & $\begin{array}{l}\text { Primers 10-11: } \sim 900 \\
\text { Primers 11-14: }\end{array}$ & NA & NA \\
\hline
\end{tabular}

NA = not applicable. $\S=$ no amplification.

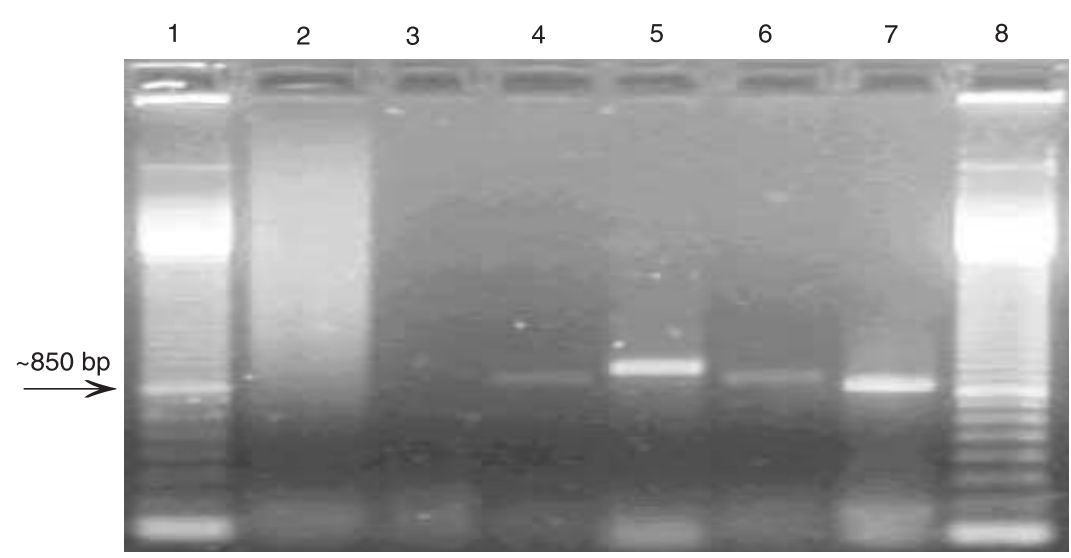

Figure 5. RT-PCR analysis for the detection of NS3 gene duplication in the genome of cytopathic bovine viral diarrhea virus (BVDV) isolates. Lane 1, Molecular weight marker (100-bp ladder); lane 2, negative control; lane 3, no template; lane 4, TGAC strain; lane 5, TGAC strain; lane 6, isolate 14; lane 7, isolate 14; lane 8, molecular weight marker. Lanes 4 and 6 show amplified products of isolates TGAC and 14 using primers 10 and 11 . Lanes 5 and 7 show the amplified products of isolates TGAC and 14 using primers 11 and 14 . RT. PCR products were submitted to $1 \%$ agarose gel electrophoresis, stained with ethidium bromide, and visualized under UV light. The size of the amplified products from the isolate containing duplication is indicated by the arrow. 
and 14. Obtaining amplicons from these RNAs by using primers 10 and 11 eliminated any possible problems with RNA quality or with PCR. This result indicates that cpBVDV isolate 14 does possess a duplication of the NS3 gene downstream of the original site that would be amplified by primers 11 and 14. Attempts to determine the complete nucleotide sequence of such genome rearrangement are currently underway.

\section{Discussion}

Analysis of the genomes of $41 \mathrm{cpBVDV}$ isolates by RT-PCR revealed that three isolates contain RNA insertions in the NS2-3 gene and one virus contains an NS3 gene duplication downstream from the original locus. The sizes of the three insertions are indistinguishable when examined by agar gel electrophoresis, their size corresponding to the NADL insert. In fact, one such insert was shown to be of the cIns type, and was highly homologous to the insert found in the genome of cpBVDV NADL. Expression of NS3 from these rearranged genomes probably occurs either by protease cleavage within the inserted sequences (for the viruses harboring inserts) or by direct translation of the NS3 polypeptide from the duplicated gene (21). In contrast, the genomes of $37 \mathrm{cp}$ isolates do not contain detectable insertions within the region examined or NS3 gene duplication. The most likely mechanism of NS3 generation in these viruses, which lack large genomic rearrangements, appears to be the presence of point mutations within the NS2 gene leading to cleavage of NS2-3 (14). Nonetheless, as the PCR analysis only focused on two sites of genomic rearrangements, we cannot rule out other possible rearrangements being responsible for NS3 expression in these viruses.

The identification of BVDV isolates capable of inducing a cytopathic effect in culture cells dates back to the late 50's (18).
However, data concerning differences of the viral genomes ( $c p / n c p)$ were not available for a long time. As a consequence, the origin of cpBVDVs and their role in the pathogenesis of mucosal disease were only elucidated three decades later $(7,22)$. Once the origin of cpBVDV was determined, molecular markers of cpBVDV at genomic and polypeptide levels were shortly identified $(11,12)$. Thereafter, expression of NS3 as a discrete polypeptide, and not as part of NS2-3 as in ncpBVDVs, was universally considered to be the molecular marker of cpBVDV (1117). As the cytopathic phenotype of BVDV is strictly correlated with the expression of NS3, and no exceptions have been reported to date, we did not investigate the expression of NS3 in all isolates. Only a few isolates were examined by Western blot to confirm the expression of NS3 as a discrete polypeptide (data not shown).

Molecular analyses of many cytopathic field isolates revealed that cpBVDVs originate from their $n c p$ counterparts by diverse genetic mechanisms, usually as a result of RNA recombination $(12,13,15,16)$. Insertions of cellular sequences, accompanied or not by duplication of viral sequences, and duplications and rearrangements of viral sequences have been identified in the genomes of cpBVDVs $(12,13,15-18,23)$. These genome alterations have been shown to be responsible for the expression of NS3. Two widely used cpBVDV strains (Osloss and NADL) were the first to have the mechanism of NS3 generation elucidated $(12,24)$. The genome of the cpBVDV Osloss strain contains an integration of a cellular sequence - a ubiquitin-coding sequence (12). The cellular homologue inserted into the NADL genome, termed cIns, has been recently identified and corresponds to sequences of the cellular J-Domain protein, a chaperonin protein (25). Further analysis of cpBVDV genomes demonstrated that integration of ubiquitin-coding sequences and cIns-like sequences within the NS2-3 gene represents a 
frequent means of generating cpBVDVs $(12,16-18,21,23,26)$. In addition, other cellular insertions have been detected in this genomic region of cpBVDV isolates, namely part of light chain 3 microtubule-associated proteins (LC3) (13), SMT3B (27), ribosomal S27a-coding sequence (28), NEDD8 cellular sequences (29), ubiquitin-like proteins, and part of a chaperon called Jiv (25). The expression of NS3 from genomes containing cellular insertions within NS2-3 probably occurs by proteolytic cleavage in the inserted sequence contained within NS2-3. In the present study, three $c p$ viruses had insertions within the NS2-3 gene. One such insert has been sequenced and showed a high nucleotide homology with the NADL cIns insert, which corresponds to sequences of a cellular gene called J-Domain protein (25). The cellular insert present in the NADL genome is essential for generation of NS3 by proteolytic cleavage of NS2-3 and production of cytopathology (24). In the present study, the nucleotide sequence of the insert in the genome of two isolates could not be determined. The size of the amplified products, taken together with their frequent occurrence, suggests that they might also be of the cIns type. Although insertions leading to proteolytic cleavage of NS2-3 seem to be the most common mechanism of generation of NS3 in cpBVDV isolates (21), other mechanisms responsible for expression of NS3 have been identified. NS3 can be expressed from a duplicated gene, associated or not with other sequence rearrangements, including duplication of $\mathrm{N}^{\text {pro }}$ right upstream of the duplicated NS3 gene (30), or from a defective genome with deletion of all structural genes (15). Recently, a novel mechanism of NS3 generation was described. BVDV CP8 contains cellular insertions and viral sequence duplications in the $\mathrm{N}$-terminal region of the polyprotein - and not in the NS2-3 boundary as most isolates characterized thus far. Thus, it is tempting to speculate that the number of mechanisms of generation of NS3 will in- crease as more cpBVDV isolates are characterized. In the present study, one isolate presented an NS3 gene duplication downstream of the original locus, yielding an amplicon of approximately 800-850 nucleotides. Attempts to determine the nucleotide sequence of this region are currently ongoing. In genomes containing a duplicated NS3 gene, the expression of NS3 polypeptide is believed to occur by direct translation of the duplicated gene $(17,21)$.

Despite the initial emphasis on cellular insertions and gene duplications as a molecular mechanism of generation of NS3, examination of a large number of isolates failed to detect such genomic alterations $(17,18,30)$. Analysis of the genome of cpBVDV Oregon, a $c p$ strain whose genome does not contain NS2-3 insertions or NS3 duplication, revealed a novel mechanism of NS3 generation (14). In the genome of BVDV Oregon and other $c p$ isolates including the Singer strain, the information necessary for NS2-3 processing resides within the NS2 gene and probably involves a set of point mutations that somehow affect the cleavability of NS2-3 (14). Regardless of the molecular mechanism leading to NS3 generation, these findings demonstrated that, in addition to RNA recombination, a different genetic mechanism, point mutations within the NS2 gene, may be responsible for the production of cpBVDV. Indeed, examination of a large number of cpBVDV isolates has indicated that this mechanism seems to be more frequent than previously expected $(17,18,30)$.

In the present study, 37 of 41 isolates apparently did not contain NS2-3 insertions or NS3 gene duplication. However, it cannot be ruled out that some of these viruses may contain genome alterations not detected by the PCR strategy employed, such as the genome rearrangements recently described (20). An important pitfall of the PCR strategy described here is that only small regions of the genome were analyzed and the choice 
of primers restricted the possible detectable genomic changes. Likewise, the limitation of resolution of agar gel electrophoresis analysis of RT-PCR products would not allow the detection of small insertions.

The results presented here demonstrate that expression of NS3 in cytopathic BVDV isolates, although frequently associated with
NS2-3 insertions and/or NS3 gene duplication, appears to be more frequently associated with cleavage of the NS2-3 polypeptide without the presence of bulk genome rearrangements. It is tempting to speculate that additional mechanisms of generation of NS3 may arise as more cpBVDV isolates are examined.

\section{References}

1. Horzinek MC. Pestiviruses - taxonomic perspectives. Arch Virol 1991; 3 (Suppl): 1-5.

2. Francki RIB, Fauquet CM, Knudson DL, Brown F. Classification and nomenclature of viruses. Fifth report of the International Committee on the Taxonomy of Viruses. Arch Virol 1991; 2: 223-233.

3. Collett MS, Larson RE, Gold C. Molecular cloning and nucleotide sequence of the pestivirus bovine virus diarrhea virus. Virology 1988; 70: 253-266.

4. Poole TL, Wang C, Popp RA, Potgieter LN, Siddiqui A, Collett MS. Pestivirus translation initiation occurs by internal ribosome entry. Virology 1995; 206: 750-754.

5. Collett MS, Larson R, Belzer SK, Retzel E. Proteins encoded by bovine viral diarrhea virus: the genomic organization of a pestivirus. Virology 1988; 165: 200-208.

6. Donis RO. Molecular biology of bovine viral diarrhea virus and its interactions with the host. Vet Clin North Am Food Anim Pract 1995; 11: 393-423.

7. Brownlie J. The pathways for bovine virus diarrhoea virus biotypes in the pathogenesis of disease. Arch Virol Suppl 1991; 3: 79-96.

8. Baker J C. The clinical manifestations of bovine viral diarrhea infection. Vet Clin North Am Food Anim Pract 1995; 11: 425-445.

9. Corapi WV, French TW, Dubovi EJ. Severe thrombocytopenia in young calves experimentally infected with noncytopathic bovine viral diarrhea virus. J Virol 1989; 63: 3934-3943.

10. Moennig $V$, Liess $B$. Pathogenesis of intrauterine infections with bovine viral diarrhea virus. Vet Clin North Am Food Anim Pract 1995; 11: 477-487.

11. Donis RO, Dubovi EJ. Differences in virus-induced polypeptides in cells infected by cytopathic and noncytopathic biotypes of bovine virus diarrhea-mucosal disease virus. Virology 1987; 158: 168-173.

12. Meyers G, Tautz N, Dubovi EJ, Thiel HJ. Viral cytopathogenicity correlated with integration of ubiquitin-coding sequences. Virology 1991; 180: 602-616.

13. Meyers $G$, Stoll $D$, Gunn M. Insertion of a sequence encoding light chain 3 of microtubule-associated proteins $I A$ and $1 B$ in a pestivirus genome: connection with virus cytopathogenicity and induction of lethal disease in cattle. J Virol 1998; 72: 4139-4148.

14. Kummerer BM, Stoll D, Meyers G. Bovine viral diarrhea virus strain Oregon: a novel mechanism for processing of NS2-3 based on point mutations. J Virol 1998; 72: 4127-4138.

15. Tautz N, Thiel HJ, Dubovi EJ, Meyers G. Pathogenesis of mucosal disease: a cytopathogenic pestivirus generated by an internal deletion. J Virol 1994; 68: 3289-3297.

16. Meyers G, Tautz N, Stark R, Brownlie J, Dubovi EJ, Collett MS, et al.
Rearrangement of viral sequences in cytopathogenic pestiviruses. Virology 1992; 191: 368-386.

17. Qi F, Ridpath JF, Lewis T, Bolin SR, Berry ES. Analysis of the bovine viral diarrhea virus genome for possible cellular insertions. Virology 1992; 189: 285-292.

18. Greiser-Wilke I, Haas L, Dittmar K, Liess B, Moennig V. RNA insertions and gene duplications in the nonstructural protein p125 region of pestivirus strains and isolates in vitro and in vivo. Virology 1993; 193: $977-980$

19. Sambrook J, Russel D. Molecular cloning: A laboratory manual Cold Spring Harbor: Cold Spring Harbor Laboratory Press; 2001.

20. Muller A, Rinck G, Thiel HJ , Tautz N. Cell-derived sequences in the $\mathrm{N}$-terminal region of the polyprotein of a cytopathogenic pestivirus. J Virol 2003; 77: 10663-10669.

21. Vilcek S, Greiser-Wilke I, Nettleton P, Paton DJ. Cellular insertions in the NS2-3 genome region of cytopathic bovine viral diarrhoea virus (BVDV) isolates. Vet Microbiol 2000; 77: 129-136.

22. Lee KM, Gillespie J H. Propagation of viral diarrhea virus of cattle in tissue culture. Am J Vet Res 1957; 18: 952-953.

23. Bolin SR, McClurkin AW, Cutlip RC, Coria MF. Severe clinical disease induced in cattle persistently infected with noncytopathic bovine viral diarrhea virus by superinfection with cytopathic bovine viral diarrhea virus. Am J Vet Res 1985; 46: 573-576.

24. Mendez E, Ruggli N, Collett MS, Rice CM. Infectious bovine viral diarrhea virus (strain NADL) RNA from stable cDNA clones: a cellular insert determines NS3 production and viral cytopathogenicity. J Virol 1998; 72: 4737-4745.

25. Rinck G, Birghan C, Harada T, Meyers G, Thiel HJ, Tautz N. A cellular J-domain protein modulates polyprotein processing and cytopathogenicity of a pestivirus. J Virol 2001; 75: 9470-9482.

26. Tautz N, Meyers G, Thiel HJ. Processing of poly-ubiquitin in the polyprotein of an RNA virus. Virology 1993; 197: 74-85.

27. Qi F, Ridpath JF, Berry ES. Insertion of a bovine SMT3B gene in NS4B and duplication of NS3 in a bovine viral diarrhea virus genome correlate with the cytopathogenicity of the virus. Virus Res 1998: 57: 1-9.

28. Becher $\mathrm{P}$, Orlich M, Thiel HJ. Ribosomal S27a coding sequences upstream of ubiquitin coding sequences in the genome of a pestivirus. J Virol 1998; 72: 8697-8704.

29. Baroth $M$, Orlich M, Thiel HJ, Becher P. Insertion of cellular NEDD8 coding sequences in a pestivirus. Virology 2000; 278: 456-466.

30. Kummerer BM, Tautz $N$, Becher $P$, Thiel $H$, Meyers $G$. The genetic basis for cytopathogenicity of pestiviruses. Vet Microbiol 2000; 77: 117-128. 